\title{
Full Paper
}

\section{Ascorbic Acid: a Promising Memory-Enhancer in Mice}

\author{
Milind Parle* and Dinesh Dhingra \\ Pharmacology Division, Department of Pharmaceutical Sciences, Guru Jambheshwar University, \\ Post Box-38, Hisar-125001, Haryana, India
}

Received January 27, 2003; Accepted July 15, 2003

\begin{abstract}
Alzheimer's disease is a progressive neurodegenerative disorder characterized by a gradual decline in memory. The occurrence of Alzheimer's disease is commonplace among the Asian population, particularly among senior citizens. The present study was undertaken to assess the potential of ascorbic acid as a memory-enhancer. Swiss mice of either sex were employed in the present investigation. Elevated plus-maze and passive-avoidance apparatus served as the exteroceptive behavioral models, and diazepam-, scopolamine-, and aging-induced amnesia served as the interoceptive behavioral models. Ascorbic acid (60, $120 \mathrm{mg} / \mathrm{kg}$ ) injected for 3 and 8 consecutive days improved learning and memory of aged mice as indicated by decreased transfer-latency and increased step-down latency. Furthermore, ascorbic acid provided protection to the young animals from scopolamine- and diazepam-induced impairment of memory. Ascorbic acid was found to be more potent than piracetam as reflected by the smaller dose, more pronounced effect, and quicker onset of action. Ascorbic acid has shown promise as a powerful memory-improving agent particularly effective in aged animals. Hence, ascorbic acid might prove to be a useful memory-restorative agent in the treatment of dementia seen in elderly individuals. The underlying mechanism of action of ascorbic acid may be attributed to its antioxidant property.
\end{abstract}

Keywords: piracetam, ascorbic acid, scopolamine, memory

\section{Introduction}

Alzheimer's disease is a progressive neurodegenerative disorder characterized by a gradual decline in memory. The occurrence of this disease is commonplace among the Asian population, particularly among senior citizens. Oxygen free radicals, the harmful byproducts of oxidative metabolism are known to cause organic damage to the living system. They are implicated in various pathological events such as mutagenesis, aging, and neurodegenerative disorders (1). Increased intake of vitamin $\mathrm{E}$ is reported to reduce the risk of Alzheimer's disease through its antioxidant property $(2,3)$. However, there are conflicting reports regarding the usefulness of vitamin $C$ in the treatment of dementia. Vitamin $C$ did not increase the mental efficiency of human beings tested for their alertness, concentration, and mood (4) on the one hand, whereas ascorbic acid administered alone or in combination with oxiracetam prevented

\footnotetext{
*Corresponding author. E-mail: mparle@rediffmail.com
}

scopolamine-induced amnesia on the other hand when mice were subjected to the habituation test (5). Neurochemical analysis of Alzheimer's disease has revealed that there is a marked reduction in acetylcholine content of the cortical and hippocampal regions of human brain. Centrally acting antimuscarinic drugs (like scopolamine) impaired learning and memory of rats (6) and human beings (7). The amnesia induced by scopolamine represented the main clinical symptom of Alzheimer's disease; and piracetam reversed this effect in both rodents and human beings. Benzodiazepinereceptor agonists such as diazepam and alprazolam have been shown to produce anterograde amnesia in rodents $(8,9)$ and human beings $(10)$, which probably represented the accessory symptoms of Alzheimer's disease.

In the light of above-described observations, the present study was undertaken to assess the potential of ascorbic acid (vitamin C) as a memory-enhancing agent employing exteroceptive and interoceptive behavioral models in mice. 


\section{Materials and Methods}

\section{Animals}

Swiss mice of either sex weighing around $18 \mathrm{~g}$ (younger ones, aged 3 months) and around $25 \mathrm{~g}$ (older ones, aged 7 months) were used in the present study. Animals were procured from the disease-free animal house of CCS Haryana Agriculture University, Hisar (Haryana, India). They were acclimatized to the laboratory conditions for 5 days before behavioral studies. The animals had free access to food and water and were provided with alternate light and dark cycles of $12 \mathrm{~h}$ each. All experiments were carried out during daytime from 0900 to $1400 \mathrm{~h}$. Institutional Animals Ethics Committee (IAEC) approved the experimental protocol and care of animals was taken as per the guidelines of CPCSEA, Department of Animal Welfare, Government of India (Reg. No. 436).

\section{Drugs}

Ascorbic acid (Hi Media, Mumbai, India), diazepam (Ranbaxy Laboratories, New Delhi, India), scopolamine hydrobromide (Sigma-Aldrich, St. Louis, MO, USA), and piracetam (UCB India, Ltd., Vapi, India) were used in the present study. Piracetam, ascorbic acid, and scopolamine hydrobromide were dissolved in normal saline. Diazepam injection (Calmpose ${ }^{\circledR}$, Ranbaxy) was diluted in normal saline. All drugs were injected intraperitoneally (i.p.). Volume of injection was $1 \mathrm{ml} / 100 \mathrm{~g}$ body weight of the mouse.

\section{Laboratory models}

Exteroceptive behavioral models: a) Elevated plusmaze, b) passive-avoidance apparatus.

Interoceptive behavioral models: a) Scopolamine-induced amnesia, b) diazepam-induced amnesia, c) aginginduced amnesia.

Elevated plus-maze: The elevated plus-maze was originally introduced as a model for studying anxiolytic agents. Later on, it was found that acquisition and retention processes of memory could also be studied using the elevated plus-maze. However, the parameters used for testing these two categories of agents were distinctly different. The procedure and end-point applied in the present study for testing learning and memory was as per the criteria described by the investigators working in the area of psychopharmacology and behavioral pharmacology $(11-14)$. Briefly, the apparatus consisted of two open arms $(16 \times 5 \mathrm{~cm})$ and two covered arms $(16 \times 5 \times 12 \mathrm{~cm})$. The arms extended from a central platform $(5 \times 5 \mathrm{~cm})$, and the maze was elevated to a height of $25 \mathrm{~cm}$ from the floor. On the first day, each mouse was placed at the end of an open arm, facing away from the central platform. Transfer-latency (TL) was taken as the time taken by mouse to move into one of the covered arms with all its four legs. TL was recorded on the first day. Cut-off time observed was $90 \mathrm{~s}$. The mouse was allowed to explore the maze for another $10 \mathrm{~s}$ and then returned to its home cage. Memory retention was examined $24 \mathrm{~h}$ after the 1 st day trial on the 2nd day.

Passive-avoidance apparatus: This was another sensitive-model employed in the present study for testing learning and memory. This apparatus (12) comprised of a box $(27 \times 27 \times 27 \mathrm{~cm})$ having three walls of wood and one wall of plexiglass, featuring a grid floor (3-mm stainless steel rods set $8-\mathrm{mm}$ apart) with a wooden platform $(10 \times 7 \times 1.7 \mathrm{~cm})$ in the center of the grid floor. Electric shock (20 V AC) was delivered to the grid floor. The box was illuminated with a $15-\mathrm{W}$ bulb during the experimental period. Training was carried out in two similar sessions. Each mouse was gently placed on the wooden platform set in the center of the grid floor. When the mouse stepped down and placed all its paws on the grid floor, shocks were delivered for $15 \mathrm{~s}$ and step-down-latency (SDL) was recorded. SDL was defined as the time taken by the mouse to step down from the wooden platform to the grid floor with all its paws on the grid floor. Animals showing SDL in the range of $2-15 \mathrm{~s}$ during the first test were used for the second session and the retention test. The second session was carried out $90 \mathrm{~min}$ after the first test. When the animals stepped down before $60 \mathrm{~s}$, electric shocks were delivered for $15 \mathrm{~s}$. During the second test, animals were removed from shock-free-zone if they did not step down for a period of $60 \mathrm{~s}$. Retention was tested after $24 \mathrm{~h}$ in a similar manner, except that the electric shocks were not applied to the grid floor. Each mouse was again placed on the platform, and the SDL was recorded, with an upper cut-off time of $300 \mathrm{~s}$.

Locomotor function: Locomotor activity of control and drug-treated animals was measured with the help of a photoactometer (INCO, Ambala, India).

Drug protocol: The animals were divided into 31 groups. Each group comprised of a minimum of 5 animals. In the present investigation, the dose selection was based on our pilot study and earlier reports (5).

Group I served as the control group for young mice. Normal saline was injected i.p. for 8 days. TL was noted at 45 min after the injection on the 8 th day and after $24 \mathrm{~h}$, that is, on the 9th day.

Group II: Scopolamine hydrobromide $(0.4 \mathrm{mg} / \mathrm{kg})$ was injected i.p. TL was noted after 45 min of injection and after $24 \mathrm{~h}$.

Group III: Diazepam (1 mg/kg) was injected i.p. TL was noted after $45 \mathrm{~min}$ of injection and after $24 \mathrm{~h}$. 
Groups IV and V: Piracetam (200 and $400 \mathrm{mg} / \mathrm{kg}$, i.p., respectively) was injected to young mice for 8 days. The last injection was given $60 \mathrm{~min}$ before subjecting the animals to the elevated plus-maze test. TL was noted on the 8 th day and after $24 \mathrm{~h}$, that is, on the 9 th day.

Group VI: Piracetam (400 mg/kg, i.p.) was injected to young mice for 8 days. At $60 \mathrm{~min}$ after the injection of piracetam on the 8th day, scopolamine hydrobromide $(0.4 \mathrm{mg} / \mathrm{kg})$ was injected i.p. TL was noted after $45 \mathrm{~min}$ of injection of scopolamine and after $24 \mathrm{~h}$, that is, on the 9 th day.

Groups VII and VIII: Ascorbic acid (60 and $120 \mathrm{mg}$ $/ \mathrm{kg}$, i.p., respectively) was injected to young mice for 3 days. The last injection was given $60 \mathrm{~min}$ before experimentation. TL was noted on the 3 rd day and after $24 \mathrm{~h}$, that is, on the 4 th day.

Groups IX and X: Ascorbic acid (60 and $120 \mathrm{mg} / \mathrm{kg}$, i.p., respectively) was injected to young mice for 8 days. The last injection was given $60 \mathrm{~min}$ before experimentation. TL was noted on the 8th day and after $24 \mathrm{~h}$, that is, on the 9th day.

Group XI: Ascorbic acid (60 mg/kg, i.p.) was injected to young mice for 3 days. At $60 \mathrm{~min}$ after the injection of ascorbic acid on the 3rd day, scopolamine hydrobromide $(0.4 \mathrm{mg} / \mathrm{kg})$ was injected i.p. TL was noted after $45 \mathrm{~min}$ of injection of scopolamine and after $24 \mathrm{~h}$, that is, on the 4th day.

Group XII: Ascorbic acid (60 mg/kg) was injected i.p. to young mice for 3 days. After 60 min of injection of ascorbic acid on the 3rd day, diazepam ( $1 \mathrm{mg} / \mathrm{kg})$ was injected i.p. TL was noted after 45 min of injection of diazepam and after $24 \mathrm{~h}$, that is, on the 4 th day.

Group XIII served as the control group for aged mice. Normal saline was injected i.p. for 8 days. TL was noted after 45 min of injection on the 8th day and after $24 \mathrm{~h}$, that is, on the 9th day.

Group XIV: Piracetam (400 mg/kg, i.p.) was injected to aged mice for 8 days. The last injection was given $60 \mathrm{~min}$ before experimentation. TL was noted on the 8th day and after $24 \mathrm{~h}$, that is, on the 9th day.

Groups XV and XVI: Ascorbic acid (60 and $120 \mathrm{mg}$ $/ \mathrm{kg}$, i.p., respectively) was injected to aged mice for 3 days. The animals were subjected to the elevated plusmaze test at $60 \mathrm{~min}$ after the last injection on the 3rd day and after $24 \mathrm{~h}$, that is, on the 4th day.

Groups XVII and XVIII: Ascorbic acid (60 and $120 \mathrm{mg} / \mathrm{kg}$, i.p., respectively) was injected to aged mice for 8 days. The animals were subjected to the elevated plus-maze test at $60 \mathrm{~min}$ after the last injection on the 8th day and after $24 \mathrm{~h}$, that is, on the 9 th day.

Group XIX: Normal saline $(1 \mathrm{ml} / 100 \mathrm{~g})$ was administered i.p. to young mice for 3 days. At $60 \mathrm{~min}$ after the administration on the $3 \mathrm{rd}$ day, SDL was recorded.
Retention was examined after $24 \mathrm{~h}$.

Groups XX and XXI: Ascorbic acid (60 and $120 \mathrm{mg}$ $/ \mathrm{kg}$, i.p., respectively) was injected to young mice for 3 days. The last injection was given $60 \mathrm{~min}$ before experimentation. SDL was noted on the 3rd day and after $24 \mathrm{~h}$, that is, on the 4th day.

Group XXII: Scopolamine hydrobromide $(0.4 \mathrm{mg} / \mathrm{kg})$ was injected i.p. after training on the 2 nd day and SDL was recorded at $45 \mathrm{~min}$ after injection.

Group XXIII: Ascorbic acid (60 mg/kg, i.p.) was injected i.p. to young mice for 3 days. SDL was recorded at $60 \mathrm{~min}$ after injection for the two training sessions. Scopolamine hydrobromide $(0.4 \mathrm{mg} / \mathrm{kg})$ was injected i.p. $45 \mathrm{~min}$ prior to recording SDL after $24 \mathrm{~h}$, that is, on the 4th day.

Group XXIV: Normal saline $(1 \mathrm{ml} / 100 \mathrm{~g})$ was administered i.p. to aged mice for 3 days. At 60 min after the administration on the 3rd day, SDL was recorded. Retention was examined after $24 \mathrm{~h}$.

Groups XXV and XXVI: Ascorbic acid (60 and $120 \mathrm{mg} / \mathrm{kg}$, i.p., respectively) was injected to aged mice for 3 days. The last injection was given $60 \mathrm{~min}$ before experimentation. SDL was noted on the 3rd day and after $24 \mathrm{~h}$, that is, on the 4th day.

Groups XXVII and XXVIII: Changes in emotional state of animals and signs of writhing syndrome were observed.

Groups XXIX, XXX, and XXXI: Effect on locomotor function of mice was studied using a photoactometer.

\section{Statistical analysis}

All the results were expressed as the mean \pm S.E.M. The data were analyzed using ANOVA (one-way analysis of variance) and Student's (unpaired) $t$-test. $P<0.05$ was considered as statistically significant.

\section{Results}

\section{Writhing syndrome}

The two doses (60 and $120 \mathrm{mg} / \mathrm{kg}$ ) selected of ascorbic acid neither showed any signs of writhing syndrome in mice nor elicited any changes in the emotional state of animals as reflected by their overall behavioral pattern within the home cage.

\section{Photoactometer}

Besides, there was no significant effect on the locomotor activity of mice treated with 60 and $120 \mathrm{mg} / \mathrm{kg}$ of ascorbic acid administered for 3 successive days (score $=222.3 \pm 7$ and 215.2 \pm 12 , respectively) as compared to the control group $($ score $=213.6 \pm 14)$ when tested using a photoactometer. 


\section{Elevated plus-maze}

Aged mice showed higher TL values on the 1st day as well as the 2nd day (after $24 \mathrm{~h}$ ) as compared to young mice, indicating impairment in learning and memory (i.e., aging-induced amnesia). Piracetam (200 and $400 \mathrm{mg} / \mathrm{kg}$ ) treatment for 8 days decreased TL on the 8th day and after $24 \mathrm{~h}$, that is, on the 9th day as compared to the saline-treated group, indicating improvement in both learning and memory. The higher dose of piracetam $(400 \mathrm{mg} / \mathrm{kg}$, for 8 days) improved learning and memory remarkably $(P<0.05)$ in both young and aged mice (Tables 1 and 2). Scopolamine hydrobromide $(0.4 \mathrm{mg} / \mathrm{kg})$ increased TL significantly on the 1st and 2nd day as compared to the saline-treated group, indicating impairment in learning and memory.
Diazepam $(1.0 \mathrm{mg} / \mathrm{kg})$ also increased TL significantly on the 1st and 2nd day as compared to the saline-treated group. Thus, both scopolamine and diazepam produced amnesia in experimental animals. Piracetam (400 mg $/ \mathrm{kg}$ ) pre-treatment for 8 days reversed impairment in learning and memory caused by scopolamine hydrobromide (Table 1).

Ascorbic acid (60 mg/kg, for 3 days) decreased TL significantly on the 3rd day and 4th day in young and aged mice (when compared to the respective control group). Thus, ascorbic acid not only improved the memory of young animals but also reversed the aginginduced amnesia (Tables 1 and 2). Ascorbic acid treatment $(60 \mathrm{mg} / \mathrm{kg}$, for 8 days $)$ significantly improved learning and memory of aged animals as reflected by

Table 1. Effect on transfer-latency (TL) of young mice using elevated plus-maze

\begin{tabular}{cllccc}
\hline Group No. & Treatment & Dose $\left(\mathrm{kg}^{-1}\right)$ & No. of animals & $\begin{array}{c}\text { TL on last day } \\
\text { of treatment (s) }\end{array}$ & TL after 24 h (s) \\
\hline I & Normal saline (Control) & $10 \mathrm{ml}$ & 6 & $28.08 \pm 4.96$ & $20 \pm 1.87$ \\
II & Scopolamine hydrobromide & $0.4 \mathrm{mg}$ & 5 & $46.7 \pm 9.94^{*}$ & $38.9 \pm 12.45^{*}$ \\
III & Diazepam & $1 \mathrm{mg}$ & 5 & $49.7 \pm 7.03^{*}$ & $30.4 \pm 6.79^{*}$ \\
IV & Piracetam (8 days) & $200 \mathrm{mg}$ & 5 & $19.6 \pm 1.36$ & $13.4 \pm 1.18$ \\
V & Piracetam (8 days) & $400 \mathrm{mg}$ & 5 & $10.8 \pm 1.19^{*}$ & $11.14 \pm 0.8^{*}$ \\
VI & Piracetam (8 days) & $400 \mathrm{mg}$ & 5 & $13.2 \pm 2.6^{\dagger}$ & $13.86 \pm 1.8^{\dagger}$ \\
& + Scopolamine & $0.4 \mathrm{mg}$ & & & \\
VII & Ascorbic acid (3 days) & $60 \mathrm{mg}$ & 5 & $13.2 \pm 1.43^{*}$ & $9.14 \pm 0.31^{*}$ \\
VIII & Ascorbic acid (3 days) & $120 \mathrm{mg}$ & 5 & $22 \pm 2.1$ & $20.1 \pm 4.8$ \\
IX & Ascorbic acid (8 days) & $60 \mathrm{mg}$ & 6 & $22.88 \pm 2.5$ & $19.36 \pm 2.03$ \\
X & Ascorbic acid (8 days) & $120 \mathrm{mg}$ & 5 & $16.94 \pm 2.97$ & $14.86 \pm 2.43$ \\
XI & Ascorbic acid (3 days) & $60 \mathrm{mg}$ & 5 & $17.42 \pm 1.82^{\dagger}$ & $17.16 \pm 1.84^{\dagger}$ \\
& + Scopolamine & $0.4 \mathrm{mg}$ & & & \\
XII & Ascorbic acid (3 days) & $60 \mathrm{mg}$ & 6 & $15.9 \pm 3.36^{\dagger}$ & $9.25 \pm 2.15^{\dagger}$ \\
& + Diazepam & $1 \mathrm{mg}$ & & & \\
\hline
\end{tabular}

Values are each a mean \pm S.E.M. * indicates $P<0.05$, as compared to the control group. ${ }^{\dagger}$ indicates $P<0.05$, as compared to the scopolamine or diazepam alone. 1st day TL: $\mathrm{F}(11,51)=11.759(P<0.05) ;$ 2nd day TL: $\mathrm{F}(11,51)=4.122$ $(P<0.05)$.

Table 2. Effect on transfer-latency (TL) of aged mice using elevated plus-maze

\begin{tabular}{|c|c|c|c|c|c|}
\hline Group No. & Treatment & Dose $\left(\mathrm{kg}^{-1}\right)$ & No. of animals & $\begin{array}{l}\text { TL on last day } \\
\text { of treatment (s) }\end{array}$ & TL after $24 \mathrm{~h}(\mathrm{~s})$ \\
\hline I & Control (young mice) & $10 \mathrm{ml}$ & 6 & $28.08 \pm 4.96$ & $20 \pm 1.87$ \\
\hline XIII & Control (aged mice) & $10 \mathrm{ml}$ & 6 & $42 \pm 3.57^{*}$ & $36.2 \pm 4.19^{*}$ \\
\hline XIV & Piracetam (8 days) & $400 \mathrm{mg}$ & 5 & $14.4 \pm 3.1^{\#}$ & $10.3 \pm 1.2^{\#}$ \\
\hline$X V$ & Ascorbic acid (3 days) & $60 \mathrm{mg}$ & 5 & $8.68 \pm 0.26^{\#}$ & $9.08 \pm 0.16^{\#}$ \\
\hline XVI & Ascorbic acid (3 days) & $120 \mathrm{mg}$ & 5 & $12.06 \pm 1.9^{\#}$ & $14.3 \pm 2.5^{\#}$ \\
\hline XVII & Ascorbic acid (8 days) & $60 \mathrm{mg}$ & 5 & $18 \pm 1.7^{\#}$ & $21.96 \pm 5.6^{\#}$ \\
\hline XVIII & Ascorbic acid (8 days) & $120 \mathrm{mg}$ & 5 & $12.8 \pm 2.2^{\#}$ & $14.04 \pm 3.7^{\#}$ \\
\hline
\end{tabular}

Values are each a mean \pm S.E.M. * indicates $P<0.05$, as compared to the control group for young mice. ${ }^{*}$ indicates $P<0.05$, as compared to the control group for aged mice. 1st day TL: $\mathrm{F}(6,29)=10.145(P<0.05)$; 2 nd day TL: $\mathrm{F}(6,29)=6.861(P<0.05)$. 
Table 3. Effect of ascorbic acid on step-down-latency (SDL) using passive-avoidance apparatus

\begin{tabular}{clllc}
\hline Group No. & Mice & Treatment & Dose $\left(\mathrm{kg}^{-1}\right)$ & SDL after 24 h (s) \\
\hline XIX & Young & Control (Saline) & $10 \mathrm{ml}$ & 113 \\
XX & Young & Ascorbic acid (3 days) & $60 \mathrm{mg} .3$ \\
XXI & Young & Ascorbic acid (3 days) & $120 \mathrm{mg}$ & $253.1 \pm 17.3^{*}$ \\
XXII & Young & Scopolamine & $0.4 \mathrm{mg}$ & $38.6 \pm 4.27^{*}$ \\
XXIII & Young & Ascorbic acid (3 days) & $60 \mathrm{mg}$ & $15.6 \pm 2.21^{*}$ \\
& & + Scopolamine & $0.4 \mathrm{mg}$ & $259 \pm 25.3^{\dagger}$ \\
XXIV & Aged & Control (Saline) & $10 \mathrm{ml}$ & $40.16 \pm 6.38$ \\
XXV & Aged & Ascorbic acid (3 days) & $60 \mathrm{mg}$ & $42.6 \pm 6.34$ \\
XXVI & Aged & Ascorbic acid (3 days) & $120 \mathrm{mg}$ & 85 \\
\hline
\end{tabular}

Values are each a mean \pm S.E.M. * indicates $P<0.05$, as compared to the vehicle-treated control (for young or aged mice). ${ }^{\dagger}$ indicates $P<0.05$, as compared to the scopolamine alone. SDL: $\mathrm{F}(7,33)=60.219$.

the marked decrease in TL on the 8th and 9th day when the animals were subjected to the elevated plus-maze test (Table 2). Higher dose of ascorbic acid (120 mg $/ \mathrm{kg}$, for 3 or 8 days) decreased the TL of the $3 \mathrm{rd} / 8$ th day and after $24 \mathrm{~h}$ in only aged mice indicating improvement in learning and memory (Table 2). However, there was no effect on TL with this dose $(120 \mathrm{mg} / \mathrm{kg})$ of ascorbic acid in young mice (Table 1). Ascorbic acid pretreatment for 3 successive days to young mice protected them against both scopolamine- and diazepam-induced amnesia (Table 1).

\section{Passive-avoidance paradigm}

Ascorbic acid $(60 \mathrm{mg} / \mathrm{kg})$ administered for 3 successive days to young mice significantly increased SDL as compared to the control group, indicating improvement of memory. Furthermore, this dose of ascorbic acid reversed scopolamine-induced amnesia as well, like in the elevated plus-maze model (Table 3 ). Furthermore, a higher dose of ascorbic acid (120 mg/kg) administered for 3 successive days to aged mice significantly increased SDL as compared to the corresponding control group for aged mice, indicating significant improvement of memory (Table 3).

\section{Discussion}

Normal aging is known to deteriorate memory in human beings. In the present study, aged animals showed impaired learning and memory due to the aging process. Oxygen free radicals are implicated in the process of aging and may be responsible for the development of Alzheimer's disease in elderly persons (15). Ascorbic acid improved memory of both young and aged animals in both the exteroceptive models employed in the present study. This effect was more pronounced in aged animals, probably because aged animals were already suffering from memory impairment due to aging. Benzodiazepine-induced amnesia appears to be mediated through benzodiazepine receptors, since flumazenil (benzodiazepine-receptor antagonist) and beta-carbolines (benzodiazepine inverse agonist) have been demonstrated to reverse benzodiazepine-induced amnesia (16). However, there are several reports showing that scopolamine-induced impairment of memory is due to cholinergic-deficits in certain brain areas and appears to be unrelated to oxygen free radicals $(6,7)$. Since ascorbic acid reversed amnesia produced by both scopolamine (anti-cholinergic agent) and diazepam in the present study, the possibility that ascorbic acid might be facilitating cholinergic transmission or inhibiting benzodiazepine receptors in some manner cannot be ruled out.

Piracetam, the first representative of a class of nootropic agents, has been shown to improve memory deficits in children and geriatric individuals (17). Piracetam (400 mg/kg, i.p.) injected for 8 successive days to young and aged mice improved learning and memory significantly and also reversed the memory-impairing effect of scopolamine in the present study. This finding substantiated the earlier reports wherein repeated injections of piracetam had improved learning abilities and memory capacities of laboratory animals $(18,19)$.

Ascorbic acid enhanced memory of mice in all the experimental models (exteroceptive as well as interoceptive models) used in the present study. Although ascorbic acid did not penetrate the blood-brain barrier, its oxidized form dehydroascorbic acid readily entered the brain by means of facilitative transport $(20,21)$. The facilitative glucose transporter (GLUT 1) present on endothelial cells at the blood-brain barrier is responsible for transport of both glucose and dehydroascorbic acid into the brain. Vitamin $\mathrm{C}$ concentrations in the brain exceeded those in blood by tenfold. However, at both 
the sites, the vitamin is stored primarily in the form of ascorbic acid. Conversion of ascorbic acid into dehydroascorbic acid forms the rate-limiting-step in accumulation of the vitamin by the brain (20). Exogenous administration of ascorbic acid over a period of 3 and 8 days on a daily basis in the present study probably resulted in high antioxidant levels in brains of mice. Furthermore, ascorbic acid was found to be more potent than piracetam in the present investigation as reflected by the smaller dose, more pronounced effect, and quicker onset of action.

Vitamin C supplementation alleviated fear in male Japanese quail chicks (22). In the light of this finding, one would expect animals to spend more time on the open arms than the covered arms (when subjected to elevated plus-maze test) due to fearlessness. However, in the present study, vitamin $\mathrm{C}$ has facilitated the entry of mice from the open arms into the covered arms, thereby indicating that fear component is probably not involved. The prospective study of Morris etal. (3) carried out in human beings showed that vitamin $\mathrm{E}$ from food reduced the risk of Alzheimer's disease, whereas in the present study, ascorbic acid showed a powerful memory-enhancing effect when administered to young and aged mice for 3 and 8 days. These findings together suggested that vitamin $\mathrm{E}$ reduced the risk of developing Alzheimer's disease and ascorbic acid possessed the potential of treating Alzheimer's disease since it reversed the amnesia-induced by aging. In any case, both vitamin $\mathrm{E}$ and vitamin $\mathrm{C}$ appear to be associated with Alzheimer's disease since plasma levels of patients suffering from Alzheimer's disease showed marked reduction in vitamin $\mathrm{C}$ and vitamin $\mathrm{E}$ content (15). Oxygen free radicals and other products of oxidative metabolism have been shown to be neurotoxic (23) and antioxidant-rich diets improved cerebellar physiology and motor learning in aged rats (24). Dehydroascorbic acid conferred dose-dependent neuroprotection in reperfused and nonreperfused cerebral ischemia by augmenting antioxidant levels in brains of mice (21). The protective effect of ascorbic acid may be attributed to its antioxidant property by virtue of which susceptible brain cells get exposed to less oxidative stress resulting in reduced brain damage and improved neuronal function, thereby enhancing the memory. Since ascorbic acid elicited more pronounced neuroprotective action in aged mice, it may prove to be a useful memoryenhancing agent to treat dementia seen in elderly individuals.

\section{Acknowledgments}

Authors are deeply grateful to Dr. R.K. Chauhan,
Vice Chancellor, Guru Jambheshwar University, Hisar (Haryana, India) for his constant encouragement and keen interest in the project. The authors are grateful to Ranbaxy Laboratories, New Delhi and UCB India, Ltd., Vapi (Gujarat, India) for the generous supply of diazepam and piracetam, respectively. This study formed a part of the major research project funded by University Grants Commission, New Delhi, India.

\section{References}

1 Nagy IZ. On the true role of oxygen free radicals in the living state, aging and degenerative disorders. Ann NY Acad Sci. 2001;928:187-199.

2 Guerrero AL, Dorada-Martinez C, Rodriguez A, Pedroza-Rios K, Borgonio-Perez G, Rivas-Arancibia S. Effects of vitamin E on ozone-induced memory deficits and lipid peroxidation in rats. Neuroreport. 1999;10:1689-1692.

3 Morris MC, Evans DA, Bienias JL, et al. Dietary intake of antioxidant nutrients and the risk of incident Alzheimer's disease in a biracial community study. JAMA. 2002;287:3230-3237.

4 Adam K. Lack of effect on mental efficiency of extra vitamin C. Am J Clin Nutr. 1981;34:1712-1716.

5 deAngelis L, Furlan C. The effects of ascorbic acid and oxiracetam on scopolamine induced amnesia in a habituation test in aged-mice. Neurobiol Learn Mem. 1995;64:119-124.

6 Higashida A, Ogawa N. Differences in the acquisition process and the effect of scopolamine on radial maze performance in the strains of rats. Pharmacol Biochem Behav. 1987;27:483-489.

7 Sitaram N, Weingartner H, Gillin JC. Human serial learning. Enhancement with arecholine and choline and impairment with scopolamine. Science. 1978;201:247-276.

8 Preston C, Ward C, Lines CR, Poppleton P, Haigh JRM, Traub M. Scopolamine and benzodiazepine models of dementia: reversal by RO-15-1788 and physostigmine. Psychopharmacology (Berl). 1989;98:487-494.

9 Singh N, Sharma A, Singh M. Possible mechanism of alprazolam-induced amnesia in mice. Phamacology. 1998;56: 46-50.

10 Lister RG. The amnesic action of benzodiazepines in man. Neurosci Biobehav Rev. 1985;9:87-94.

11 Itoh J, Nabeshima T, Kameyama T. Utility of an elevated plus maze for the evaluation of nootropics, scopolamine and electro convulsive shock. Psychopharmacology (Berl). 1990;101:27-33.

12 Reddy DS, Kulkarni SK. Possible role of nitric oxide in the nootropic and antiamnesic effects of neurosteroids on aging and dizocilpine-induced learning impairment. Brain Res. 1998; 799:215-229.

13 Veerendra Kumar MH, Gupta YK. Effect of different extracts of Centella asiatica on cognition and markers of oxidative stress in rats. J Ethnopharmacol. 2002;79:253-260.

14 Dhingra D, Parle M, Kulkarni SK. Effect of combination of insulin with dextrose, D (-)-fructose and diet on learning and memory in mice. Indian J Pharmacol. 2003;35:151-156.

15 Sinclair AJ, Bayer AJ, Johnston J, Warner C, Maxwell SR. Altered plasma antioxidant status in subjects with Alzheimer's disease and vascular dementia. Int J Geriatr Psychiatry. 1998; 13:840-855. 
16 Jensen LH, Stephens DN, Sarter M, Petersen EN. Bidirectional effects of beta-carbolines and benzodiazepines on memory processes. Brain Res Bull. 1987;19:359-364.

17 Tariska P, Paksy A. Cognitive enhancement effect of piracetam in patients with mild cognitive impairment and dementia. Orv Hetil. 2000;141:1189-1193.

18 Canonico PL, Aronica E, Aleppo G, et al. Repeated injections of piracetam improve spatial learning and increase the stimulation of inositol phospholipid hydrolysis by excitatory amino acids in aged rats. Funct Neurol. 1991;6:107-111.

19 Bhattacharya SK, Upadhyay SN, Jaiswal AK. Effect of piracetam on electroshock induced amnesia and decrease in brain acetylcholine in rats. Indian J Exp Biol. 1993;31:822-824.

20 Agus DB, Gambhir SS, Pardridge WM, et al. Vitamin C crosses the blood-brain barrier in the oxidized form through the glucose transporters. J Clin Invest. 1997;100:2842-2848.
21 Huang J, Agus DB, Winfree CJ, et al. Dehydroascorbic acid, a blood-brain barrier transportable form of vitamin C, mediates potent cerebroprotection in experimental stroke. Proc Natl Acad Sci USA. 2001;98:11720-11724.

22 Jones RB, Satterlee DG, Cadd GG. Timidity in Japanese quail: effects of vitamin $\mathrm{C}$ and divergent selection for adrenocortical response. Physiol Behav. 1999;67:117-120.

23 Sayre LM, Zagorski MG, Surewicz WK, Krafft GA, Perry G. Mechanisms of neurotoxicity associated with amyloid beta deposition and the role of free radicals in the pathogenesis of Alzheimer's disease: a critical appraisal. Chem Res Toxicol. 1997;336:1216-1222.

24 Bickford PC, Gould T, Briederick L, et al. Antioxidants-rich diets improve cerebellar physiology and motor learning in aged rats. Brain Res. 2000;866:211-217. 